\title{
Inverse Calculation of Timber-CFRP Composite Beams Using Finite Element Analysis
}

\author{
Khaled Saad $^{1 *}$, András Lengyel $^{1}$ \\ ${ }^{1}$ Department of Structural Mechanics, Budapest University of Technology and Economics, H-1521 Budapest, P.O.B. 91, Hungary \\ * Corresponding author, e-mail: khaled.saad@epito.bme.hu
}

Received: 25 May 2020, Accepted: 02 December 2020, Published online: 11 December 2020

\begin{abstract}
This study focuses on the flexural behavior of timber beams externally reinforced using carbon fiber-reinforced polymers (CFRP). Linear and non-linear finite element analysis were proposed and validated by experimental tests carried out on 44 timber beams to inversely determine the material properties of the timber and the CFRP. All the beams have the same geometrical properties and were loaded under four points bending. In this paper the general commercial software ANSYS was used, and three- and twodimensional numerical models were evaluated for their ability to describe the behavior of the solid timber beams. The linear elastic orthotropic material model was assumed for the timber beams in the linear range and the 3D nonlinear rate-independent generalized anisotropic Hill potential model was assumed to describe the nonlinear behavior of the material. As for the CFRP, a linear elastic orthotropic material model was introduced for the fibers and a linear elastic isotropic model for the epoxy resin. No mechanical model was introduced to describe the interaction between the timber and the CFRP since failure occurred in the tensile zone of the wood. Simulated and measured load-mid-span deflection responses were compared and the material properties for timber-CFRP were numerically determined.
\end{abstract}

\section{Keywords}

spruce, CFRP, reinforcement, material properties, inverse computation, finite element

\section{Introduction}

Currently wood is a widely used material for different types of structures especially the lightweight constructions. The increasing of the loads such as the dead loads and the aging of timber may be significant reasons for the demolition of some pre-existing structures. In most cases, the cost of replacement of the destroyed timber structures is high so it may be preferable to repair or strengthen the timber elements. Some conventional strengthening/reinforcing methods for wood structures are used such as using steel plates or bars, and sometimes aluminum plates. These types of methods, yet, could lead to an increase in the dead loads, high transportation, and installation costs. It is important to mention that some traditional rehabilitation methods and procedures may force us to use some mechanical connections such as bolts, nails and so on. On the other hand, this could not involve good reactions from the deteriorated timber elements since the steel components are oversensitive to corrosion, add to this the aluminum plates may buckle when applying thermal loads. Nowadays, it is advisable to use the fiber-reinforced polymer (FRP) composites which may reduce these kinds of problems and which might also be a permanent solution to strengthen timber elements due to their many advantages such as corrosion resistance, lightweight and flexibility, high elastic modulus and high strength, especially when the load-bearing capacity and the ductility are in demand to be increased.

The application of fiber-reinforced plastic materials started many years ago in the 1960s when the use of fiberglass (GFRP) for the strengthening of the timber structures took place [1]. Nowadays, in some engineering applications, the engineers started to use the carbon fiber reinforced polymers (CFRP) which have recently proved their significantly positive effects on the structural behavior: enhancing the structural performance of sawn timber beams or glued-laminated beams, increasing the ductility and bearing capacity of the timber elements. Furthermore, for rehabilitating and repairing the pre-existing structures such as bridges or historic structures. Usually, the reinforcing elements are sheets or rods parallel to grains and 
they may be connectors or pultruded elements as well. The reinforcing materials are usually glued to the tension side of the element since they help to increase the load-bearing capacity and sometimes enhance the bending stiffness, flexural capacity, and ductility of the timber-FRP structural elements; as for their application, the reinforcing materials which are usually CFRP or GFRP are inserted in the timber elements, e.g. Borri et al. [2] proposed a method to investigate the effect of the CFRP on the flexural stiffness and capacity of historical timber structural elements. Four-point-bending experimental analysis was also provided to validate the numerical model. They presented an equation that explains the mechanical behavior of wood elements subjected to tension. A maximum of $60 \%$ increase in capacity and $30 \%$ in stiffness were reported. Different ratios of wood Young's modulus to CFRP modulus were found which is due to the plasticization in the zone under compression. Valluzzi et al. [3] investigated two strengthening techniques for spruce wood for already existing structures, the dry connection with a timber flange at the upper side, and a sheet of CFRP at the underside. On timber strengthening, see also $[4,5]$.

The studies on the reinforcement of timber aim to improve the flexural capacity, ductility, and sometimes the stiffness of the timber elements, and they, fortunately, yield quite good results in a wide range of engineering practice. The results showed that the load-bearing capacity has increased by approx. 20-50\% and sometimes higher $[2,6]$. It was also shown that in most cases stiffness will not be affected at all by the presence of the reinforcements $[7,8]$ but some researchers revealed an increase of almost $30 \%$. The influence of the CFRP and GFRP on the behavior of Pinus Caribea Var. Hondurensis wood species was studied in [9]. Fibers were manually attached to timber beams in the tension zone glued with epoxy resin. Experimental as well as theoretical investigations (with the help of Navier/ Bernoulli model) showed an average increase of $19.175 \%$ in bending stiffness when the CFRP was applied manually to the timber elements. CFRP fibers with a modulus of elasticity 59,000 MPa and tensile strength $1034 \mathrm{MPa}$ were used by Tingley and Kent [10], an increase of $21.5 \%$ in the strength and $4.69 \%$ in the stiffness were observed, compared with results obtained for beams without reinforcement. Analytical, experimental, and FEA studies investigating the effect of unidirectional CFRP laminate of different length and an elastic modulus of $160.7 \mathrm{GPa}$ were performed by de Jesus et al. [4]. They showed an increase in elastic stiffness by $23 \%$ and $28 \%$.
The effect of externally bonded CFRP lamellas on the increase of stiffness and capacity of the timber beams was also studied in [11]. The stiffness increase was not recognized and the theoretical ratio of the wood-CFRP modulus of elasticity to the obtained experimental values was compared and significant differences were found.

The increase of the carrying capacity of reinforced beams varies mainly according to the nature of the element to be strengthened, the wood species, the type of fiber used, the layout of the reinforcement in the element, the volume of FRP, and the integrity of the bonding surface between FRP and timber.

The failure mode of timber elements is often due to transverse tension. Timber as known has a natural heterogeneous character, and the mechanical behavior of timber beams is directly affected by the presence of knots, splits, and slope of grains. Two failure modes can be identified when reinforcing a timber beam with CFRP: the first one is failure due to tension which is the dominant one, while the other occurs when the compression stress limit is reached $[5,12]$. To predict the ultimate flexural capacity of wood, Liu [13], Hasebe and Usuki [14], Patton-Mallory et al. [15] suggested using the Tsai-Wu strength theory for anisotropic materials.

Defects and faults in the wood are dangerous especially when they are found in the tensile zone, and under tension they tend to develop cracks and reduce the capacity and stiffness of the beams. Fortunately, these deteriorations can be stopped by using strengthening composite materials for the exposed surface of the beams.

Experimental and finite element analysis were done in [16] to locally reinforce defected spruce wood beams by D-shape CFRP strip in the vicinity of the knots (modeled as openings with different diameters) assuming a linear elastic response for CFRP. Wood was modeled as linear elastic orthotropic material and tested in the elastic range by four-point bending. The general statement is that knot usually cause a stress disturbance only in its vicinity (local effect), therefore, it is not economical to reinforce the whole beam and the application of local reinforcements will be beneficial to increase the bending stiffness if we consider a CFRP with at least 16-times higher value of Young's modulus in comparison to spruce wood.

Many authors proposed finite element models to study the behavior of Norway spruce wood members, e.g. [16-19]. Rafsanjani et al. [20] numerically predicted the swelling of the hierarchical cellular structure of Norway spruce softwood assuming a transverse anisotropic model. Furthermore, a finite element model to simulate the behavior and 
to predict the maximum bending capacity of timber Pinus sylvestris $L$. beams subjected to four-point bending considering an orthotropic elastoplastic constitutive law in a plane stress state was shown by Baño et al. [21]. Mechanical tests were also investigated to validate the model. The material model in compression was predicted according to Hill and as for tension, it was considered linear elastic until rupture. A 2D finite element model in-plane stress state was assumed for Douglas Fir [22]. Transversally isotropic (5 independent material properties for the elastic behavior) with anisotropic plasticity was assumed to study the behavior of Scots pine P. Sylvestris wood with the help of 3D finite element models [23]. With the help of the finite element method, a bilinear anisotropic hardening model, which is a generalization of the Hill model, was used to simulate the behavior of wood [24]. The same model was also used by Shih and Lee [25]. Furthermore, Buchanan in his work assumed the stress-strain curve for wood, elastic-plastic behavior for compression, and a linear elastic for tensile stresses [26].

Although wood is highly anisotropic material, the linear orthotropic material model can be always applied to analyze the behavior of wood in the pure elastic state. However, linear and nonlinear models along with experimental investigations have been proposed by many authors for the evaluation of the complex behavior of carbon reinforced timber beams [27, 28].

More studies on the determination of material properties have been proposed. An example was presented to analyze the variations of the wood elastic parameters concerning the Young's moduli and shear moduli in the LT and LR planes, modeled as a linear elastic orthotropic material in terms of the so-called Euler's angles $(\lambda, \rho)$ introduced by Hermanson, along with some experimental investigations [29, 30]. A 3D model considering the elastic-plastic behavior of Norway Spruce (Picea abies) was constructed using the (FE) approach with the help of the Generalized Anisotropic Hill Potential Model. The model was validated by three-point static bending and compression tests to determine the properties of the analyzed material. At first, the material properties were calculated experimentally applying analytical equations provided by the British Standard Institute 1957. In the next step, the properties were modified by numerically fitting the obtained load deflection curves to the experimental curves. It was assumed that the wood behaves in the linear state as an elastic, semi-rigid in tension, and nonlinear ductile behavior in the state of compression [31].
An example was also presented about a theoretical model that was applied to determine the Young's modulus of Laminated Veneer Lumber (LVL) reinforced by CFRP considering that the LVL is homogeneous and the fibers of the CFRP are unidirectional [32]. Another example was presented by Da Silva Bertolini et al. [33] where the product inertia EI of the epoxy resin-reinforced timber historical structural element was determined experimentally.

Moreover, the CFRP elastic properties were predicted using a mathematical approach along with an experimental analysis for sake of comparison and verification [34]. Unidirectional compressive strength of CFRP were predicted by applying analytical models [35]. Models and equations presented by $\mathrm{Hu}$ [36] were also applied to predict the modulus of elasticity of wood-fiberboard.

As discussed previously, results related to stiffness are different for each case, and this is mainly due to the use of different reinforcement types, and the characteristics of the timber used. The binder material, usually a polymeric resin, does not contribute that much to the increase of the strength properties, but it holds the whole system together to make it act as a composite member. The gain in stiffness is influenced by the elastic moduli and allowable stresses of the component materials.

The important fact should be addressed that the effectiveness of the CFRP in terms of its stiffness is significantly affected by the method of application (in-situ or prefabricated). In former research with the collaboration of the authors, experiments were conducted showing an apparently moderate increase of stiffness [37], which was in correspondence with several other reported results as shown above. Based on the test setup, approximately $70 \%$ theoretical increase of stiffness was expected, highlighting the importance of the applied method of reinforcement and suggesting that in situ reinforcement of timber using CFRP is not preferable if the target is to increase the stiffness.

The objective of this study is to examine the composite structure of a timber beam made of spruce fitted with CFRP composites to the tension side and to find the material properties of its constituents including the effective stiffness of the fiber reinforcement. Experiments have been previously done on Picea abies (Norway spruce) wood species, which are native to Europe [37]. Regarding the reinforcement, they are made of the high quantity of carbon fiber fabric embedded in epoxy resin (matrix), these experiments aimed to determine the increase of the flexural capacity and the stiffness of the reinforced timber beams with CFRP, thus, to verify the positive effects and the efficiency of the 
reinforcement. Using these experimental data, 3D and 2D finite element models were created using ANSYS coupled with MATLAB considering elastic and elastic-plastic material models to numerically reproduce the measured loaddeflection curves. A series of numerical computations are aimed to determine the unknown material parameters.

\section{Experimental procedure}

The experiments in the related study by the authors involved Norway spruce (Picea abies) fitted with CFRP fabric. The dimensions of the investigated specimens were $95 \mathrm{~mm} \times 95 \mathrm{~mm} \times 1800 \mathrm{~mm}$ and their moisture content at the time of experimental testing was about $12 \%$ (see [37] for more details).

Forty-four member configurations were modeled (see Table 1) aiming to prove that the type of reinforcement as well as wood species, etc. are the most important factors which affect significantly on the potential improvement of the structural behavior and to support the conclusions with statistical analysis.

The four-point bending test, see Fig. 1, was used for each specimen. In the testing European standards were followed to set the geometric parameters of the beams. To ensure appropriate measurement, a standard MTS test authorized device with a capacity of $250 \mathrm{kN}$ was used in a certified timber structural testing laboratory. Each specimen has a cross-section of $95 \mathrm{~mm} \times 95 \mathrm{~mm}$ and $1800 \mathrm{~mm}$ long. The shear span-to-depth ratio was $a / h=6.31$, well within the allowable range of 5-12, where $a$ is the distance from the support to the nearest point load and $h$ is the depth of the beam. Specimens were constrained by a simply supported, pin-roller foundation. The load heads were applied at the third points along the length of the beam.

The measurement data of load to mid-span deflection relationship for all test specimens are shown in Fig. 2. Each curve comprises linear and nonlinear parts. The loading was also a measured parameter during the experimental analysis with the help of a testing device and a video extensometer, and digital records have been saved for the analysis.

Table 1 Specimen configuration

\begin{tabular}{lcc}
\hline Test group & $\begin{array}{c}\text { CFRP fabric } \\
\text { reinforcement }\end{array}$ & Number of specimens \\
\hline S0 & none & 8 \\
S1 & $\begin{array}{c}\text { l layer, full width } \\
(1.4 \text { mm thick })\end{array}$ & 20 \\
S2 & $\begin{array}{c}\text { layers, full width } \\
(2.8 \text { mm thick })\end{array}$ & 8 \\
SN & $\begin{array}{c}\text { layer, } 50 \text { mm width } \\
(1.4 \text { mm thick })\end{array}$ & 8 \\
\hline
\end{tabular}

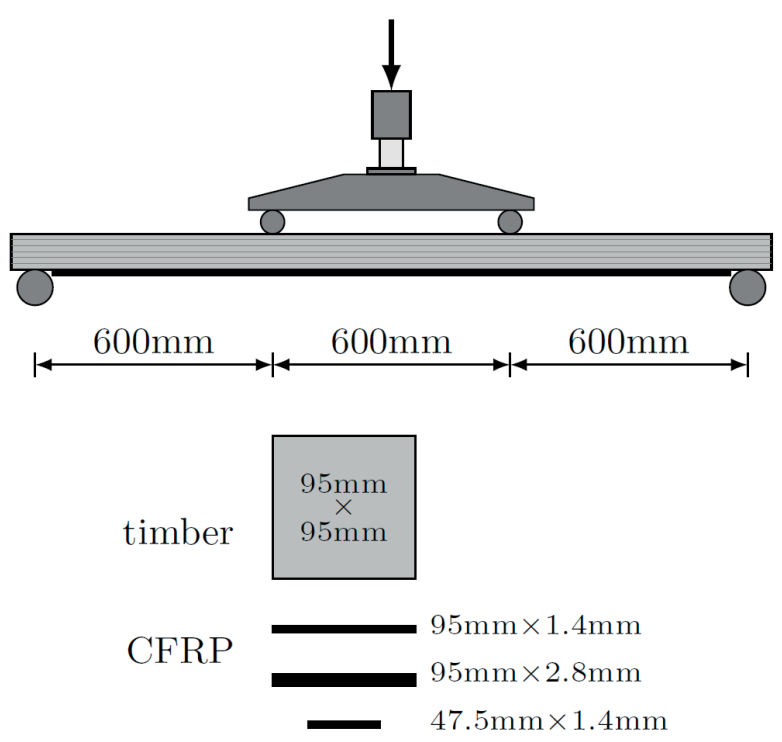

Fig. 1 Sketch of test arrangement and cross-sections with various reinforcement types

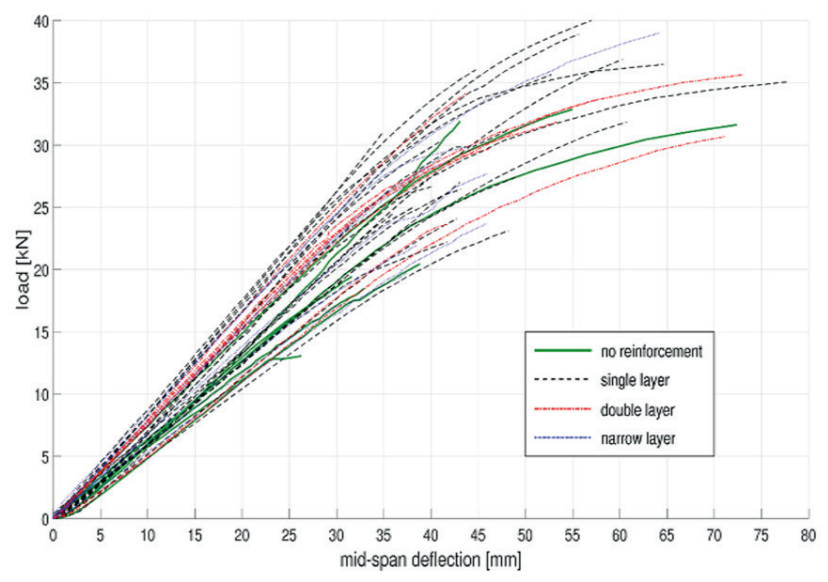

Fig. 2 Load-deflection curves for all test specimens. Curves referring to test groups S0 (no reinforcement), S1 (single layer), S2 (double layer), and SN (narrow layer) are plotted with thick solid, thin dashed, thin dash-dot, and thin solid lines, respectively [37]

S0, S1, S2, and SN are plotted in thick solid, thin dashed, thin dash-dot, and dotted lines, respectively. The reinforcement did not lead to significantly increase the stiffness values of the wood-CFRP system.

\section{Numerical modeling 3.1 Model generation}

A 3D FE model was used proposed to perform the analysis and to predict the load-deflection curves of the rectangular solid timber beams strengthened by CFRP under fourpoint bending as well as to inversely determine the elastic and plastic material properties of wood and the elastic properties of the CFRP. 


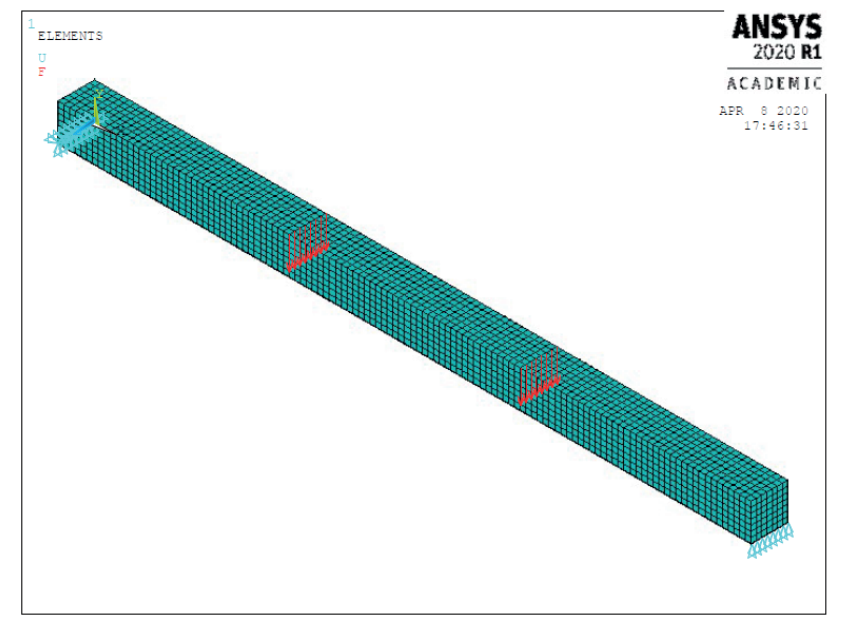

Fig. 3 Loading, boundary conditions, and element type

Numerical simulations were done using FE available in ANSYS. Fig. 3 schematically illustrates the loading and the boundary conditions of the 3D finite element model.

An 8-node solid element with reduced integration (three translational degrees of freedom per node) was used to model the timber beams. The FE mesh of the timber beam consisted of 5880 brick elements type SOLID45.

Because the fiber-reinforced polymers are relatively thin compared to the timber beam, CFRP fabrics were modeled by a smeared reinforcement layer (consists of 840 REINF265 elements) embedded in a layer of epoxy represented by 840 SOLID185 elements. Fig. 4 shows the solid elements of the epoxy (a) and the placement of the smeared reinforcement layer inside (b). The CFRP elements were directly attached to the bottom surface of the timber beam, and the interaction between CFRP and timber was considered to be bonded since de-bonding did not occur in the experiments.

Furthermore, because all loads and displacements were in-plane and there was no variation in geometry, supports, and loads in the transverse direction, two-dimensional plane stress assumptions were also applied for simplicity and for this purpose 2D finite element models were developed and the 8-node plane element (three degrees of freedom per node) was used to model the timber beams. Fig. 5 shows the 3D view of the 2D model (a) and a scaled 3D view that highlights the right lowermost series of elements corresponding to the CFRP (b). The FE mesh of the timber beam consisted of 900 elements type PLANE183. CFRP fabrics were modeled by shell elements with membrane options (SHELL181).

The loads are transferred to the beam on the top surface at one and two thirds of the beam longitudinally, and distributed evenly transversely (z direction), see Fig. 3.

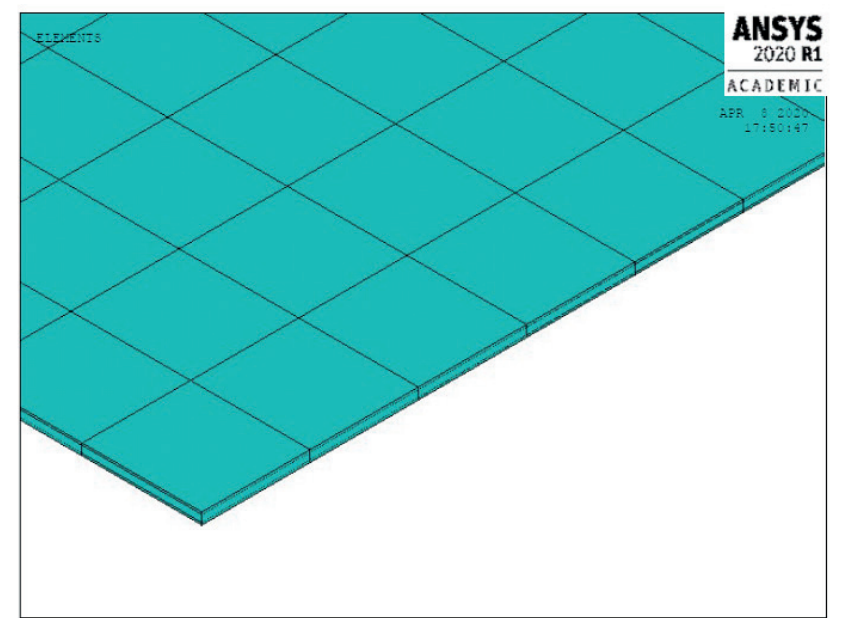

(a)

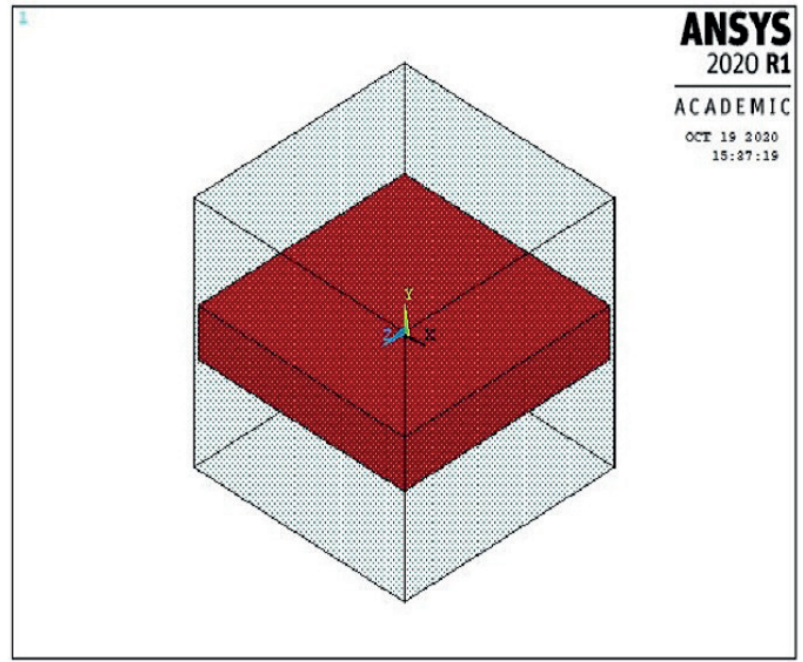

(b)

Fig. 4 Epoxy-FRP model: solid elements of the epoxy (a) and the placement of the smeared reinforcement layer inside (b)

Technically, two series of concentrated forces were applied on nodes along these lines, while boundary conditions were applied to each node located along the bottom edges to constrain the member and to generate the simply supported system.

The proposed material models have been created with the help of general-purpose finite element analysis software ANSYS mechanical APDL for defining the mechanical constitutive equations of the wood material and CFRP.

\subsection{Constitutive modeling of wood}

\subsubsection{Linear analysis}

An elastic orthotropic constitutive relationship for timber elements could be established using the general form of Hooke's law with nine independent material constants as $\boldsymbol{\sigma}=\mathbf{D} \boldsymbol{\varepsilon}$, where $\boldsymbol{\sigma}=\left[\sigma_{L} \sigma_{R} \sigma_{T} \tau_{L R} \tau_{L T} \tau_{R T}\right]^{T}$ is the stress vector with indices $L, R$, and $T$ refers to longitudinal, radial, and 


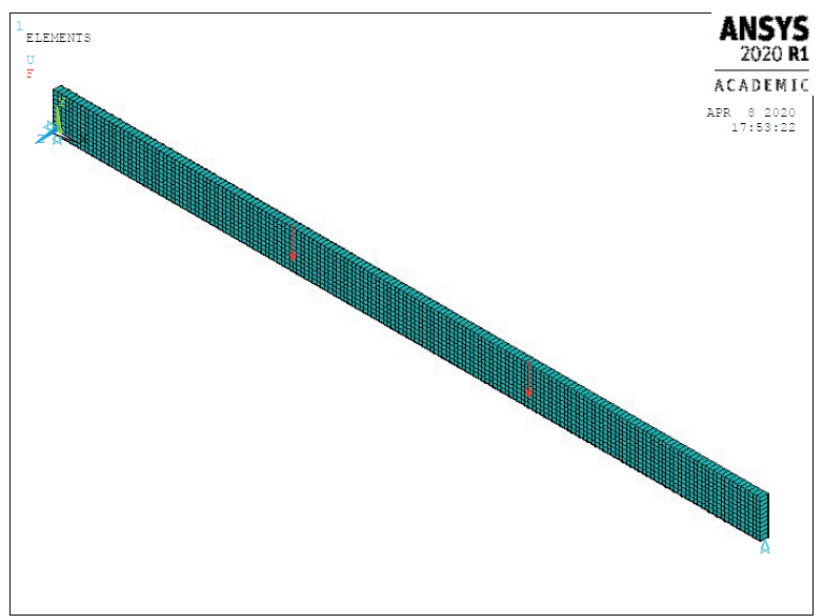

(a)

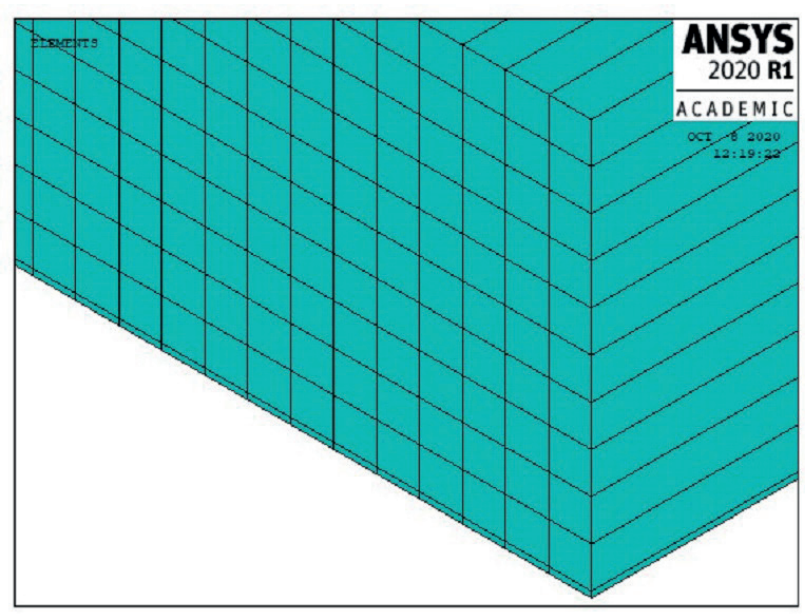

(b)

Fig. 5 2D plane stress finite element model: 3D view of the 2D model (top) and a scaled 3D view that highlights the right lowermost series of elements corresponding to the CFRP (bottom)

tangential directions, respectively, in the local fiber aligned coordinate system of wood; $\boldsymbol{\varepsilon}=\left[\varepsilon_{L} \varepsilon_{R} \varepsilon_{T} \gamma_{L R} \gamma_{L T} \gamma_{R T}\right]^{T}$ is the strain vector in the same system, and $\mathbf{D}$ is the orthotropic material stiffness matrix.

The orthotropic stiffness matrix D was built with the engineering properties of the timber species which will be determined later. The material properties are independent of loading rates. The effects of the environment such as moisture and temperature on the behavior of timber species were not taken into consideration.

During the finite element calculation, the eigenvalues of all the minors matrices of the stiffness matrix should be positive including the determinant of the full matrix to make sure that the stiffness matrix is positive definite; in another word, the following relation between the elastic modulus and Poisons ratios should be also positive:
$R=1-v_{R L}^{2} \frac{E_{L}}{E_{R}}-v_{T R}^{2} \frac{E_{R}}{E_{T}}-v_{T L}^{2} \frac{E_{L}}{E_{T}}-2 v_{R L} v_{T R} v_{T L} \frac{E_{L}}{E_{R}}$,

where $E_{i}(i=L, R, T)$ are the moduli of elasticity of wood and $v_{i j}=(i, j=L, R, T)$ are the Poison's ratios.

\subsubsection{D nonlinear analysis: Hill elastic-plastic model}

The timber beams subjected to tensile loads, present a linear elastic-quasi rigid behavior, and when subjected to compression the wood undergoes a linear-elastic behavior and a nonlinear inelastic (perfectly plastic or isotropic hardening bilinear) behavior as well. This is why the beam fails for tension in most cases. Therefore, a structural nonlinear inelastic and rate-independent anisotropic material model, the so-called generalized anisotropic Hill potential model was used to simulate the nonlinear behavior of the timber beams. The generalized Hill plasticity model considers different yield strength in tension than in compression. This material model is used to simulate the anisotropic and asymmetric tension-compression behavior for materials which are characterized by low crystallographic symmetries such as natural and processed wood products (fabricated timber beams) and fiber-matrix composites. In general cases, the material properties required by Hill model are the compression yield stresses in longitudinal $(x)$, radial $(y)$, and tangential $(z)$ directions $\left(\sigma_{c x}, \sigma_{c y}\right.$, and $\sigma_{c z}$ respectively) and the corresponding tangent moduli $\left(E_{t x}, E_{t y}, E_{t z}\right)$, the tensile yield stresses $\left(\sigma_{t x}, \sigma_{t y}\right.$, and $\sigma_{t z}$ respectively) and the corresponding tangent moduli. Furthermore, shear yield stresses in the material $x y, y z$, and $x z$ directions and the corresponding tangent moduli.

A bilinear anisotropic stress-strain relationship is used to enable the individual components of tension and compression yield stresses. The plastic or yield surfaces correspond to the Hill model (see Fig. 6), has an anisotropic work-hardening rule, and an associated flow rule.

The main assumption for the plasticity is that the strains are divided into two independent elastic and plastic parts as

$\varepsilon=\varepsilon_{\mathrm{e}}+\varepsilon_{\mathrm{p}}$.

\subsubsection{D nonlinear analysis}

The in-plane longitudinal components of the total stress are the dominant stresses in case of tension that is why it is enough practically to consider a 2D model. Simplification for the variation between the radial, tangential, and longitudinal properties was applied and the out of plane properties was not considered in the analysis since significant 


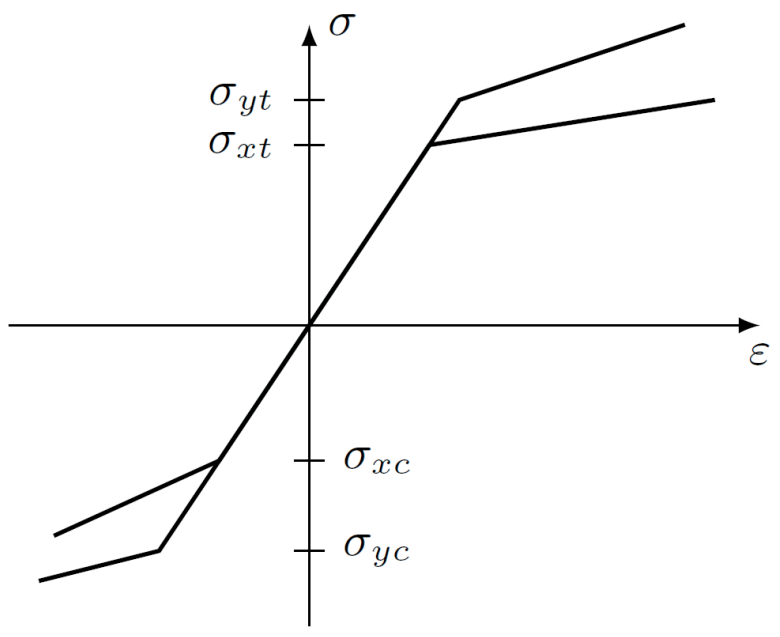

Fig. 6 Stress-strain relationship for timber beam (Hill anisotropic) [38]

stresses and strains are not expected in the transverse direction. Therefore, a linear isotropic material model followed by a bilinear isotropic hardening model was selected for wood assuming an elastic-plastic behavior in compression, and a linear elastic until rupture for tension.

For the 2D plane stress - the stress-strain relationship is as follows:

$$
\left[\begin{array}{c}
\sigma_{x} \\
\sigma_{y} \\
\tau_{x y}
\end{array}\right]=\left[\begin{array}{ccc}
\frac{E}{1-v^{2}} & \frac{E v}{1-v^{2}} & 0 \\
\frac{E v}{1-v^{2}} & \frac{E}{1-v^{2}} & 0 \\
0 & 0 & \frac{E}{2(1+v)}
\end{array}\right]\left[\begin{array}{c}
\varepsilon_{x} \\
\varepsilon_{y} \\
\gamma_{x y}
\end{array}\right] .
$$

\subsection{Constitutive modeling of CFRP}

Reinforcements result in shifting the neutral axis of the timber beam downward and this in turn allows greater plastic deformation in the compression zone; therefore, the ductility of the reinforced beams is increased, and the failure mechanism is changed. Numerically there are two methods to model the mechanical behavior of the CFRP: (1) the CFRP material behaves as a linear elastic isotropic material, or (2) the CFRP behaves as a linear elastic orthotropic material. In bending tests, during which the CFRP is attached along with the grain orientation, the longitudinal modulus is the parameter of the highest importance. An orthotropic model was considered here taken into consideration significantly low stiffness in the plane perpendicular to the longitudinal axis. The tensile modulus of elasticity in the fiber direction of the unidirectional CFRP material was provided by the manufacturer $\left(E_{f}=234 \mathrm{GPa}\right)$.

\subsection{Characteristics of materials}

\subsubsection{Wood}

Norway spruce timber is one of the most well-known species in Northern, Central, and Eastern Europe. The wood material is generally assumed orthotropic, requiring a significant number of properties for its complete characterization. This wood species has specific characteristics including Young's moduli, shear moduli, and Poisson's ratios, compression yield stresses, tangent modulus and maximum tensile strength which are available in some engineering books [39]; therefore, no tests were performed to find reference values of the mechanical properties of the modeled timber beams for the analysis.

This study aims to determine the material properties of the timber beams as well as for CFRP under consideration which are capable to produce the same experimentally load-deflection curves.

Based on sensitivity analysis, which was performed parametrically by changing the material properties that do not belong to the longitudinal direction (x direction) and evaluate their effects on the overall behavior of woodCFRP system in terms of the load-deflection curve, it was found that the overall behavior depends only on the wood components related to the longitudinal direction (x-direction) and other parameters have negligible effect; therefore, the elastic and inelastic properties of wood to be determined are as follows: longitudinal Young's modulus $E_{x}$, longitudinal compression yield stress $\sigma_{c x}$, longitudinal compression tangent modulus $E_{t x}$, ultimate longitudinal tensile stress $\sigma_{t x}$. However, other material properties were set according to literature data [39], the magnitude of these properties are very small compared to the longitudinal ones. For Spruce wood the following ratios are recommended:

$$
\begin{aligned}
& \frac{E_{Z}}{E_{X}}=0.034, \\
& \frac{E_{Y}}{E_{X}}=0.078, \\
& \frac{G_{X Y}}{E_{X}}=0.046, \\
& \frac{G_{X Z}}{E_{X}}=0.061, \\
& \frac{G_{Y Z}}{E_{X}}=0.003 .
\end{aligned}
$$


Therefore, the wood modulus of elasticity in the vertical direction (Y direction) - $E_{y}$ for instance can reach up to $1 \mathrm{GPa}$ and this value has a very negligible effect on the results in terms of deflections and stresses. When multiplying its magnitude by 2 , the value of the obtained ultimate displacement is decreasing by $0.0017 \%$.

These material properties are first set on a set of average parameter values, which are representative for Norway spruce. The average material properties for spruce wood are shown in Table 2.

\subsubsection{CFRP}

The only characteristic of the CFRP used to reinforce the timber beams, taken from the manufacturer's data sheets is the nominal value of the longitudinal Young's modulus, $E_{C F R P}$ see [37]. CFRP fabrics were manually attached to the tension side of the timber beams to allow greater plastic deformation in the compression zone; therefore, to increase the ductility of the reinforced beams.

The law of mixture states that $E_{\text {comp }}=V_{f} E_{f}+V_{e} E_{e}$, where $V$ denotes the volume fraction and indices $f$ and $e$ refer to the fiber and the epoxy, respectively. Considering that $99 \%$ of composite is fibers (as provided by the manufacturer), therefore $E_{\text {comp }}=231 \mathrm{GPa}$. Fibers have a high modulus within fiber direction but if the force is not applied within fiber direction, this modulus is dramatically decreased. Yet, only fibers within the load direction show the effectiveness of the modulus.

The only material property of the CFRP that is unknown is the longitudinal tensile Young's modulus $E_{C F R P}$ (denoted by $E_{r}$ later).

\section{Principle of inverse analysis}

The inverse analysis in our study is the process of recalculating the load-deflection curves from a set of assigned material properties for wood and CFRP that produced them. It is named an inverse analysis since it starts with the results, in other words, with the material properties that we are looking for. This kind of analysis is one of the most important analyses in science and mathematics because they tell us about parameters that we cannot directly observe. Combining ANSYS with MATLAB creates a powerful tool

Table 2 Spruce material properties [39]

\begin{tabular}{lll}
\hline$E_{L}=9900 \mathrm{MPa}$ & $\mu_{L R}=0.39$ & $G_{T L}=610 \mathrm{MPa}$ \\
$E_{R}=730 \mathrm{MPa}$ & $\mu_{L T}=0.49$ & $G_{R T}=22 \mathrm{MPa}$ \\
$E_{T}=410 \mathrm{MPa}$ & $\mu_{R T}=0.64$ & $G_{L R}=500 \mathrm{MPa}$ \\
$\begin{array}{l}\text { Average compression yield } \\
\text { strength parallel to the grain }\end{array}$ & $\sigma_{c L}=30 \mathrm{MPa}$ & \\
\hline
\end{tabular}

for such parametric analysis; therefore, the inverse analysis can be performed as follows: (1) with the help of MATLAB macro files are created, (2) ANSYS is called to run in batch mode in order to perform the analysis, (3) collect results in form of load-deflection curves, (4) for each specimen, simulated load-deflection curves are compared with a single experimental curve, (5) chose the material properties related to the best fit load-deflection curve.

A 4D grid was analyzed where each of the material properties to be calculated has their own range for different rounds as follows. An average of 4 rounds was needed, in the first round an initial grid was chosen where modulus of elasticity for wood $E_{w}$ ran between $7 \mathrm{GPa}$ and $12 \mathrm{GPa}$ in steps of 1 , wood compression tangent modulus $E_{t x}$ between 0 and $5 \mathrm{GPa}$ in steps of $1 \mathrm{GPa}$, compression yield stress of wood $\sigma_{c x}$ between $25 \mathrm{MPa}$ and $50 \mathrm{MPa}$ in steps of $1 \mathrm{MPa}$, FRP modulus of elasticity between $20 \mathrm{GPa}$ and $240 \mathrm{GPa}$ in step of $20 \mathrm{GPa} .11232$ input files were generated with the help of MATLAB and the obtained numerical loaddeflection curves were compared with a single experimental one. In the next rounds, the discrete optimum of the error function in the grid is located. Assuming that the optimum is in the neighborhood of the discrete optimum, a finer grid is created around it and the analysis is rerun on that grid.

The indicator of fitting is the error function, that is, the integral of the square of the difference between the simulated and the measured curves:

$f_{\text {err }}=\int_{0}^{F_{\max }}\left(e_{s}-e_{m}\right)^{2} \mathrm{~d} F$,

where $F_{\max }$ is the ultimate load of the specimen, $e_{s}$ and $e_{m}$ refer to the simulated and the measured displacement data, respectively. The measurements are given as discrete points, and the simulated function is also evaluated at discrete points. Between points piecewise linear functions are assumed hence the integration can be formulated easily.

The inverse analysis is considered "inverse" to the problem which relates the model material properties to the results (load-deflection curve). The analysis requires starting with an assumed stress-strain diagram for each specimen and find out; after the analysis, its load-deflection curve which should be the same as found in the experiment.

\section{Results and discussion}

\subsection{Load-deflection curve}

Initially the load-deflection curve showed a linear behavior until the wood starts to yield in compression. After yielding the beams showed a nonlinear behavior, with reduced stiffness up to failure. 
The quasi-static loading technique is not only to predict accurate failure capacities but also to attempt to model the member behavior during a loading event. Therefore, with the finite element results, load-deflection curves were plotted to compare the behavior of the model with the load-deflection curves provided by the previously done experiments which in turn will correspond to the material properties of wood-CFRP materials. Figs. 7 to 10 are plots of the load-deflection curves obtained from the 3D finite element analyses along with the load-deflection data obtained from the entire sample of specimens tested for each respective case.

Fig. 7 is the plot of a selected specimen in the control group (S0) with no reinforcements. The dominant failure mode of the model was the tensile failure. Comparing the failure load of the control model to the models where timber beams are reinforced indicates an increase in flexural capacity. In each case containing reinforcements, failure always initiated in timber. The non-linear effects were included in all the models.

Figs. 8-10 are load-deflection curves for selected cases in groups $\mathrm{S} 1, \mathrm{~S} 2$, and $\mathrm{SN}$, respectively. All cases were modeled using the load-stepping technique to model the nonlinear behavior. As can be seen in the figures, the 3D FEA results fall well within the spread of the experimental data.

The failures always initiated at the tension zone of the timber, which is the location where the material cannot undergo any plastic deformation. However, this can lead in most cases to lose the capacity in compression which in turn leads to obtain a low ductile member. Furthermore, Fig. 11 highlights the differences between the 3D, 2D finite element models, and the experimental load-deflection curves for a single reinforced beam.

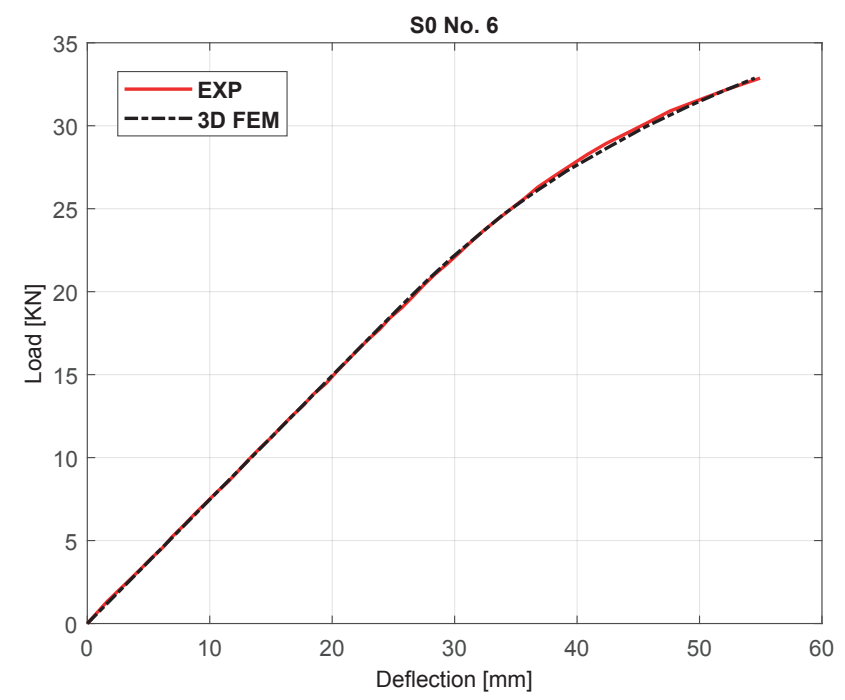

Fig. 7 Non reinforced beam S0 (specimen No. 6)

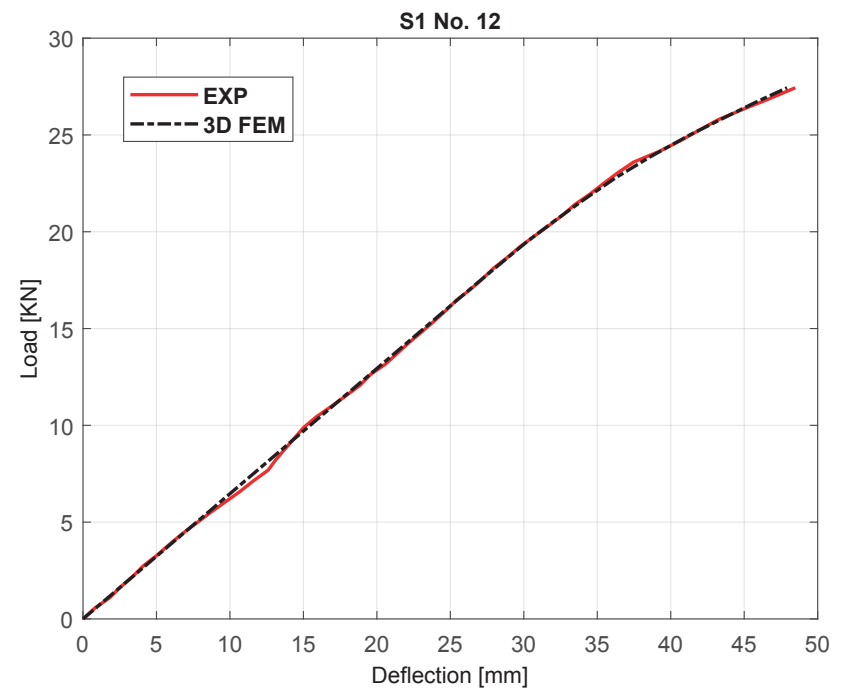

Fig. 8 Single layer reinforced beam S1 (specimen No. 12)

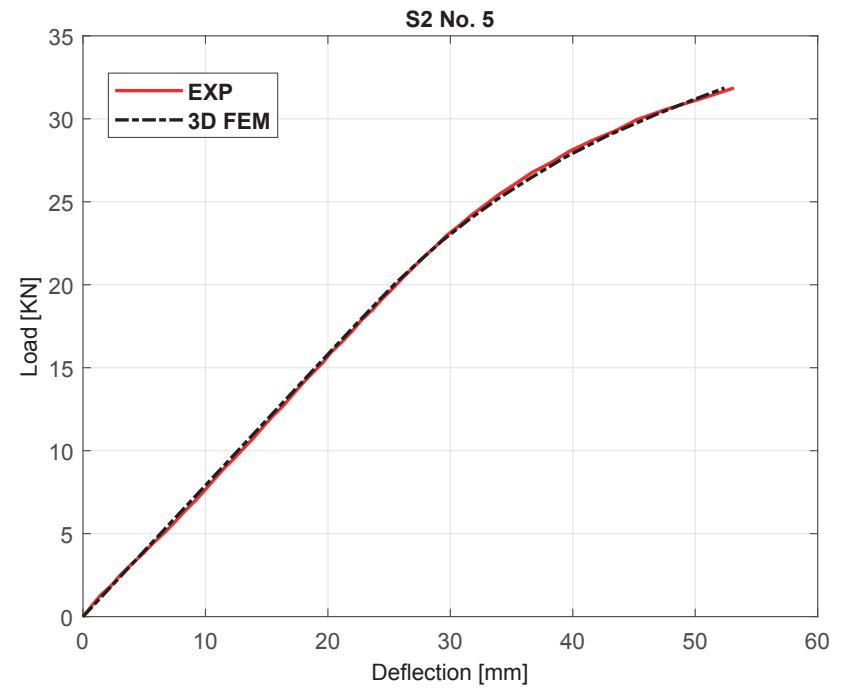

Fig. 9 Double-layer reinforced beam S2 (specimen No. 5)

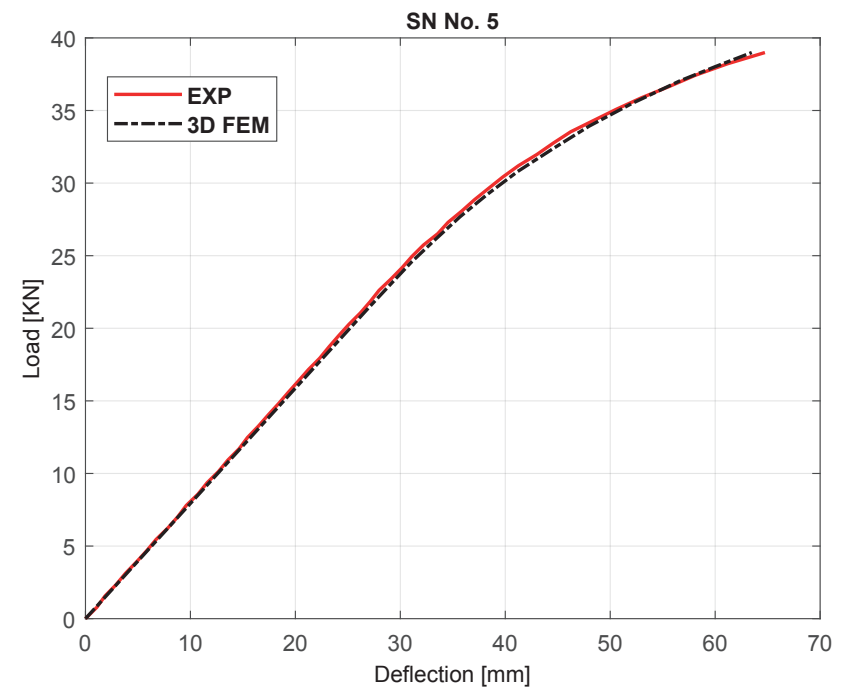

Fig. 10 Half-layer reinforced beam SN (specimen No. 5) 


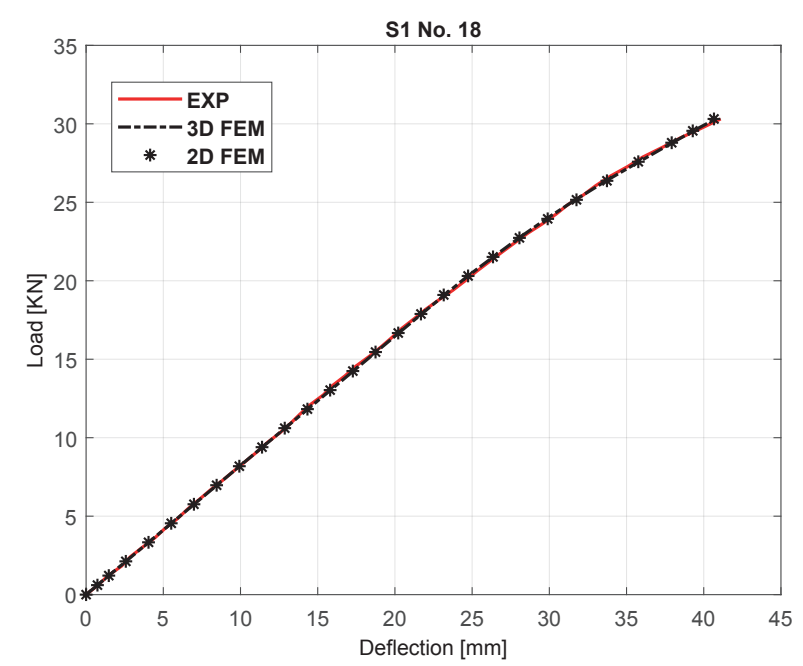

Fig. 11 3D, 2D, and experimental load-deflection curves (S1 No. 18)

\subsection{Material properties}

The selected specimens shown in the previous subsection provide a good sample of the general behavior. Table 3 summarizes the statistics of the results for both the $2 \mathrm{D}$ and the 3D finite element models. The numbers in the table are the mean values of the parameters in each group with corresponding standard deviations shown in parentheses.
3D Hill anisotropic material model can model both tension and compression behavior in wood. Therefore, the bilinear stress-strain relationship in compression especially with perfect plasticity can capture the trend of the load-deflection curves in most cases. The average modulus of elasticity of the wood material is $9369.831 \mathrm{~N} / \mathrm{mm}^{2}$ with an average relative standard deviation of $20.04 \%$. The average compression yield stress is $33.22 \mathrm{~N} / \mathrm{mm}^{2}$ with a relative standard deviation of $18.66 \%$. As for the reinforcements, the average moduli of elasticity are $59710 \mathrm{~N} / \mathrm{mm}^{2}$ with large relative standard deviations.

The 2D finite element model, which considers both elastic tensions, and inelastic compression (bilinear hardening) gives also similar results (see Table 3), as apparent through the examples shown in the previous subsection. Large immediate loss of load-bearing capacity reflected by the significant drop of the slope of the load-deflection curve is found which is due to rupture in the tension zone. This excessive behavior was not exhibited by any of the test specimens, except just before the collapse. Hence, the non-linearity of the structure is not only due to the tensile rupture.

Table 3 Mean values of optimal material parameters (wood modulus $E_{W}=E_{L}$, reinforcement modulus $E_{r}$, wood compression yield stress $\sigma_{c x}=\sigma_{c L}$, the wood tensile maximum stress $\sigma_{t x}=\sigma_{t L}$, and wood tangent modulus $E_{t x}$ ) in all specimen groups for all models (3D and 2D). Standard deviations are given in parentheses

\begin{tabular}{|c|c|c|c|c|c|}
\hline Group & Type & Material property $(\mathrm{MPa})$ & $\begin{array}{l}\text { 3D model } \\
\text { (Hill) }\end{array}$ & $\begin{array}{l}\text { 2D model } \\
\text { (BISO) }\end{array}$ & $\begin{array}{c}\% \text { of } \\
\text { difference }\end{array}$ \\
\hline \multirow{4}{*}{$\begin{array}{l}\text { No reinforcement } \\
\text { (S0) }\end{array}$} & \multirow{4}{*}{ Wood } & Longitudinal Young's modulus $E_{W}$ & $10388.75(1275.46)$ & $9842.375(1066.54)$ & 5.55 \\
\hline & & Longitudinal compression yield stress $\sigma_{c x}$ & $30.714(7.88)$ & $30.227(8.35)$ & 1.61 \\
\hline & & Longitudinal compression tangent modulus $E_{t x}$ & $1585.71(1989.49)$ & $1628.85(2548.50)$ & 2.72 \\
\hline & & Ultimate longitudinal tensile stress $\sigma_{t x}$ & $54.95(20.77)$ & $54.53(20.29)$ & 0.77 \\
\hline \multirow{5}{*}{$\begin{array}{l}\text { Reinforced with } \\
1 \text { layer (S1) }\end{array}$} & \multirow{4}{*}{ Wood } & Longitudinal Young's modulus $E_{W}$ & $8883.7(1614.34)$ & $8502.7(1762.15)$ & 4.48 \\
\hline & & Longitudinal compression yield stress $\sigma_{c x}$ & $35.203(6.53)$ & $34.873(6.66)$ & 0.946 \\
\hline & & Longitudinal compression tangent modulus $E_{t x}$ & $547.31(1477.87)$ & $609.63(1520.96)$ & 11.38 \\
\hline & & Ultimate longitudinal tensile stress $\sigma_{t x}$ & $46.35(13.01)$ & $47.76(15.22)$ & 3.04 \\
\hline & CFRP & Fiber's modulus of elasticity $E_{r}$ & $74717.2(42.32)$ & $74713(41.56)$ & $5.62 \mathrm{e}-3$ \\
\hline \multirow{5}{*}{$\begin{array}{l}\text { Reinforced with } \\
2 \text { layers (S2) }\end{array}$} & \multirow{4}{*}{ Wood } & Longitudinal Young's modulus $E_{W}$ & $8431.25(1486.4)$ & $8260(1577.62)$ & 2.07 \\
\hline & & Longitudinal compression yield stress $\sigma_{c x}$ & $32.854(3.13)$ & $33.1125(2.89)$ & 0.786 \\
\hline & & Longitudinal compression tangent modulus $E_{t x}$ & $326.5(922.64)$ & $375.25(1060)$ & 14.93 \\
\hline & & Ultimate longitudinal tensile stress $\sigma_{t x}$ & $44.93(11.85)$ & $48.08(13.75)$ & 7.01 \\
\hline & CFRP & Fiber's modulus of elasticity $E_{r}$ & $40846(21.2)$ & 41125 (19.92) & 0.68 \\
\hline \multirow{5}{*}{$\begin{array}{l}\text { Reinforced with } \\
\text { a half layer (SN) }\end{array}$} & \multirow{4}{*}{ Wood } & Longitudinal Young's modulus $E_{W}$ & $9900.625(1497.38)$ & $9533.375(1443.82)$ & 3.85 \\
\hline & & Longitudinal compression yield stress $\sigma_{c x}$ & $34.13(7.15)$ & $33.71(6.72)$ & 1.24 \\
\hline & & Longitudinal compression tangent modulus $E_{t x}$ & $1150(1253.69)$ & 1171.25 (1257.94) & 1.84 \\
\hline & & Ultimate longitudinal tensile stress $\sigma_{t x}$ & $53.63(10.97)$ & $53.75(10.65)$ & 0.22 \\
\hline & CFRP & Fiber's modulus of elasticity $E_{r}$ & $63591.5(33.46)$ & $62975.25(32.68)$ & 0.97 \\
\hline
\end{tabular}




\subsection{Discussion}

Important conclusions are obtained with the help of the 3D and 2D numerical models applied for the wood-CFRP materials. Materials tested in the experimental analysis were obtained from the same origin possessing similar properties and following the same application technique. Properties of wood obtained with the help of the numerical simulations are in the range characteristic of this species with given standard deviations.

For the specimen groups with different reinforcement set no observable significant differences. 3D Hill anisotropic and 2D models had practically identical results in terms of the elastic and plastic mechanical properties. The finite element analysis was perfectly able to follow and capture the non-linearity in compression of wood applying potential hardening beyond the elastic limit until failure. Nevertheless, the non-linearity in the wood material is observed to be different in terms of the tangent modulus. The perfectly plastic behavior in the compression zone of the wood where the tangent modulus is zero was in most cases a good adjustment for both models to capture the curvature of the load-defection diagram and to obtain a significantly better fit. The tangent moduli are somewhat scattered in a range covering both positive and null values. Therefore, the compression behavior is changing from an individual specimen to another.

Although the wood material in tension was modeled as a linear elastic, the rupture should be modeled in a more refined way since tension rupture occurred in some of the specimens during the loading process causing a gradual micro and macro local failures at different locations, that is because wood is a natural material and wood grains have different strength naturally. This effect can be captured considering wood models that should be able to attribute different properties for different parts of the cross-section along with an appropriate parameterization. However, the full progressive failure in most specimens occurred after localized rupture failures in the tension zone indicating the effects of the weak points on the overall behavior of the timber material. Defects and knots in the timber material are among the most significant weak points that may affect the reliability of the specimens. The measured ultimate capacity of each specimen reflects these variations. The compression capacity in the timber material is not fully utilized due to the early tensile failure, which indicates that the ductility of the beams varies in a range depending on when the rupture took place.
The CFRP materials applied in the tension zone of the timber beams help to reduce the tensile stresses of the wood-CFRP system which in turn helps in increasing the ductility of the latter as well as achieving higher ultimate load. Yet, an important difference between the reinforced and unreinforced beams implies that the plastic compression capacity of the wood is utilized to a higher degree before failure.

The modulus of the reinforcement material obtained for all of the specimens is below the nominal theoretical value of the carbon fiber provided by the manufacturer (i.e. $234 \mathrm{kN} / \mathrm{mm}^{2}$ ). The in-situ preparation method of CFRP fabric is one of the most significant reasons. The glue was spread on the surface of the tension zone of the timber beams with a roller so the matrix and the bond to the timber can be obtained simultaneously. This method can provide a perfect bond between fibers and timber and efficiently applicable to be applied in arbitrary positions. Yet, the sensitivity of the extremely thin fibers to any action such as bending and axial tension is an indicator of the disadvantages of this method since the fibers in the lamellae may undergo damage to some degree. Geometric imperfections of the fibers (such as waviness) are also bound to be introduced, further reducing the modulus of elasticity. Since the thickness of the fabric is greater than usual and the consistency of the epoxy is high, much strength is required to make the epoxy penetrate the fabric, so its effect is significant. The elastic modulus is also found to be smaller in case of double reinforcement due to the large induced disturbance during the application of the epoxy which requires a larger pressure. The low increase of stiffness has been reported also in other researches. A considerable increase in capacity can be achieved however with a negligible increase of stiffness. H. Alhayek and Svecova [40] recommended not to consider fiber reinforcement to enhance stiffness. Regarding the low increase in stiffness, see also other papers, e.g. [4, 9, 11].

The values of the elastic modulus of reinforcement obtained in this study agreed perfectly with the increased stiffness obtained from the measurements. If the analysis relies on the assumed nominal value of the elastic modulus of the fiber by the provider; then over $65 \%$ increase in stiffness should be reported by performing a simple calculation of the strength of materials. The imperfections and waviness of the fibers can be captured with the help of a detailed finite element model which will be a continuation of this research. 


\section{Conclusions}

In this research the material properties of CFRP-wood composite were inversely determined with the help of numerical parametric technique along with the loaddeflection curves. The viability of the technique has been represented through a progression of information acquired from four-point bending tests led in past research on Spruce timber strengthened with CFRP fabrics. The technique scans for the ideal arrangement of model constants that limits the distinction between the simulated and the measured load-deflection curves. The optimal material properties were found by applying two distinctive numerical models for wood and two models for reinforcement separately for every specimen. The obtained properties of wood are in the average range explicit to the

\section{References}

[1] Theakston, F. H. "A feasibility study for strengthening timber beams with fiberglass", Canadian Agricultural Engineering, 7(1), pp. 17-19, 1965.

[2] Borri, A., Corradi, M., Grazini, A. "A method for flexural reinforcement of old wood beams with CFRP materials", Composites Part B: Engineering, 36(2), pp. 143-153, 2005.

https://doi.org/10.1016/j.compositesb.2004.04.013

[3] Valluzzi, M. R., Garbin, E. Modena, C. "Flexural strengthening of timber beams by traditional and innovative techniques", Journal of Building Appraisal, 3(2), pp. 125-143, 2007. https://doi.org/10.1057/palgrave.jba.2950071

[4] de Jesus, A. M. P., Pinto, J. M. T., Morais, J. J. L. "Analysis of solid wood beams strengthened with CFRP laminates of distinct lengths", Construction and Building Materials, 35, pp. 817-828, 2012. https://doi.org/10.1016/j.conbuildmat.2012.04.124

[5] Corradi, M., Maheri, A., Osofero, A. I. "Design of Reinforced and Unreinforced Timber Beams subject to Uncertainties", In: Topping, B. H. V., Iványi, P. (eds.) Proceedings of the Twelfth International Conference on Computational Structures Technology, Civil-Comp Press, Stirlingshire, UK, Paper 134, 2014.

https://doi.org/10.4203/cep.106.134

[6] Gentile, C., Svecova, D., Rizkalla, S. H. "Timber Beams Strengthened with GFRP Bars: Development and Applications", Journal of Composites for Construction, 6(1), pp. 11-20, 2002. https://doi.org/10.1061/(asce)1090-0268(2002)6:1(11)

[7] Amy, K., Svecova, D. "Strengthening of dapped timber beams using glass fibre reinforced polymer bars", Canadian Journal of Civil Engineering, 31(6), pp. 943-955, 2004.

https://doi.org/10.1139/104-063

[8] de la Rosa García, P., Escamilla, A. C., García, M. N. G. "Bending reinforcement of timber beams with composite carbon fiber and basalt fiber materials", Composites Part B: Engineering, 55, pp. 528-536, 2013.

https://doi.org/10.1016/j.compositesb.2013.07.016 species being referred to. The calculations have indicated that the because of geometrical defects and potential damage are the main reasons why the effective stiffness of the fiber material is decreased contrasted with the hypothetical qualities. The strategy has given significant information on the physical abilities of the present reinforcing procedure.

The load-deflection data along with the inverse determination of material properties helped in acquiring important information on the global behavior of full-size beams.

\section{Acknowledgments}

The presented work was conducted with the financial support of the K119440 project of the Hungarian National Research, Development, and Innovation Office.

[9] Fiorelli, J., Dias, A. A. "Analysis of the strength and stiffness of timber beams reinforced with carbon fiber and glass fiber", Materials Research, 6(2), pp. 193-202, 2003. https://doi.org/10.1590/s1516-14392003000200014

[10] Kent, S., Tingley, D. "Structural Evaluation of Fiber Reinforced Hollow Wood Beams", In: Innovative Wooden Structures and Bridges, IABSE Conference Report 85, Lahti, Finland, 2001, pp. 367-372. https://doi.org/10.2749/222137801796348845

[11] Neubauerová, P. "Timber beams strengthened by carbon-fiber reinforced lamellas", Procedia Engineering, 40, pp. 292-297, 2012. https://doi.org/10.1016/j.proeng.2012.07.097

[12] Borri, A., Corradi, M., Vignoli, A. "New materials for strengthening and seismic upgrading interventions", In: International Workshop Ariadne, Prague, Czech Republic, 2002, pp. 22-28.

[13] Liu, J. Y. "Evaluation of the Tensor Polynomial Strength Theory for Wood", Journal of Composite Materials, 18(3), pp. 216-226, 1984. https://doi.org/10.1177/002199838401800302

[14] Hasebe, K., Usuki, S. "Application of Orthotropic Failure Criterion to Wood, Journal of Engineering Mechanics", 115(4), pp. 867-872, 1989.

https://doi.org/10.1061/(asce)0733-9399(1989)115:4(867)

[15] Patton-Mallory, M., Pellicane, P. J., Smith, F. W. "Modeling Bolted Connections in Wood, Journal of Structural Engineering", 123(8), pp. 1054-1062, 1997. https://doi.org/10.1061/(asce)0733-9445(1997)123:8(1054)

[16] Burawska, I., Mohammadi, A. H., Widmann, R., Motavalli, M. "Local reinforcement of timber beams using D-shape CFRP strip", presented at SMAR 2015 - Third Conference on Smart Monitoring, Antalya, Turkey, Sept, 7-9, 2015.

[17] $\mathrm{Hu}, \mathrm{M}$. "Studies of the fibre direction and local bending stiffness of Norway spruce timber: for application on machine strength grading", Doctoral thesis, Linnaeus University, 2018. [online] Available at: http://lnu.diva-portal.org/smash/record. jsf?pid=diva2 $\% 3$ A $1172057 \&$ dswid $=9881$ 
[18] Briggert, A., Hu, M., Olsson, A., Oscarsson, J. "Tracheid effect scanning and evaluation of in-plane and out-of-plane fibre direction in Norway spruce using", Wood and Fiber Science, 50(4), pp. 411-429, 2018 https://doi.org/10.22382/wfs-2018-053

[19] Foley, C. "A three-dimensional paradigm of fiber orientation in timber", Wood Science and Technology, 35(5), pp. 453-465, 2001. https://doi.org/10.1007/s002260100112

[20] Rafsanjani, A., Lanvermann, C., Niemz, P., Carmeliet, J., Derome, D. "Multiscale analysis of free swelling of Norway spruce", Composites Part A: Applied Science and Manufacturing, 54, pp. 70-78, 2013. https://doi.org/10.1016/j.compositesa.2013.07.005

[21] Baño, V., Arriaga, F., Soilán, A., Guaita, M. "Prediction of bending load capacity of timber beams using a finite element method simulation of knots and grain deviation", Biosystems Engineering, 109(4), pp. 241-249, 2011. https://doi.org/10.1016/j.biosystemseng.2011.05.008

[22] Williams, J. M., Fridley, K. J., Cofer, W. F., Falk, R. H. "Failure modeling of sawn lumber with a fastener hole", Finite Elements in Analysis and Design, 36(1), pp. 83-98, 2000.

https://doi.org/10.1016/s0168-874x(00)00010-x

[23] Guindos, P., Guaita, M. "A three-dimensional wood material model to simulate the behavior of wood with any type of knot at the macro-scale", Wood Science and Technology, 47(3), pp. 585-599, 2013. https://doi.org/10.1007/s00226-012-0517-4

[24] Valliappan, S., Boonlaulohr, P., Lee, I. K. "Non $\square$ linear analysis for anisotropic materials", International Journal for Numerical Methods in Engineering, 10(3), pp. 597-606, 1976. https://doi.org/10.1002/nme.1620100309

[25] Shih, C. F., Lee, D. "Further Developments in Anisotropic Plasticity", Journal of Engineering Materials and Technology, 100(3), pp. 294302, 1978. https://oi.org/10.1115/1.3443493

[26] Bazan, I. M. M. "Ultimate bending strength of timber beams", Doctoral thesis, Technical University of Nova Scotia, 1980.

[27] Raftery, G. M., Harte, A. M. "Nonlinear numerical modelling of FRP reinforced glued laminated timber", Composites Part B: Engineering, 52, pp. 40-50, 2013. https://doi.org/10.1016/j.compositesb.2013.03.038

[28] Khelifa, M., Vila Loperena, N., Bleron, L., Khennane, A. "Analysis of CFRP-strengthened timber beams", Journal of Adhesion Science and Technology, 28(1), pp. 1-14, 2014. https://doi.org/10.1080/01694243.2013.815096

[29] Mascia N. T., Lahr, F. A. R. "Remarks on orthotropic elastic models applied to wood", Materials Research, 9(3), pp. 301-310, 2006. https://doi.org/10.1590/s1516-14392006000300010

[30] Hermanson, J. C. "The triaxial behavior of redwood using a new confined compression device", University of Wisconsin-Madison, Madison, WI, USA, 1997
[31] Milch, J., Tippner, J., Sebera, V., Brabec, M. "Determination of the elasto-plastic material characteristics of Norway spruce and European beech wood by experimental and numerical analyses", Holzforschung, 70(11), pp. 1081-1092, 2016. https://doi.org/10.1515/hf-2015-0267

[32] Wei, P., Wang, B. J., Zhou, D., Dai, C., Wang, Q., Huang, S. "Mechanical Properties of Poplar Laminated Veneer Lumber Modified by Carbon Fiber Reinforced Polymer", BioResources, 8(4), pp. 4883-1898, 2013.

https://doi.org/10.15376/biores.8.4.4883-4898

[33] Da Silva Bertolini, M., de Macedo, L. B., de Almeida, D. H., Icimoto, F. H., Lahr, F. A. R. "Restoration of Structural Timber Elements Using Epoxy Resin: Analysis of Mechanical Properties", Advanced Materials Research, 778, pp. 582-587, 2013. https://doi.org/10.4028/www.scientific.net/amr.778.582

[34] Rahmani, H., Najaf, S. H. M., Ashori, A., Golriz, M. "Elastic Properties of Carbon Fibre-Reinforced Epoxy Composites", Polymers and Polymer Composites, 23(7), pp. 475-482, 2015. https://doi.org/10.1177/096739111502300706

[35] Leopold, C., Harder, S., Philipkowski, T., Liebig, W. V., Fiedler, B. "Comparison of Analytical Approaches Predicting the Compressive Strength of Fibre Reinforced Polymers", Materials, 11(12), Article number: 2517, 2018.

https://doi.org/10.3390/ma11122517

[36] Hu, Y. C. "Predicting Modulus of Elasticity for Wood-Based Composites", Materials Science Forum, 575, pp. 1106-1110, 2008. https://doi.org/10.4028/www.scientific.net/msf.575-578.1106

[37] Andor, K., Lengyel, A., Polgar, R., Fodor, T, Karácsonyi, Z. "Experimental and statistical 'analysis of spruce timber beams reinforced with CFRP fabric", Construction and Building Materials, 99, pp. 200-207, 2015.

https://doi.org/10.1016/j.conbuildmat.2015.09.026

[38] Ansys, Inc. "ANSYS advanced analysis techniques guide", ANSYS, Canonsburg, PA, USA, 2001.

[39] Szalai, J. "A faanyag és faalapú anyagok anizotróp rugalmasság-és szilárdságtana. I. rész. A mechanikai tulajdonságok anizotrópiája" (The anisotropic flexibility and strength theory of the tree and tree-based materials, Part I. Anisotropy of mechanical properties), Erdészeti és Faipari Egyetem, Sopron, Hungary, 1994. (in Hungarian)

[40] Alhayek, H., Svecova, D. "Flexural Stiffness and Strength of GFRPReinforced Timber Beams", Journal of Composites for Construction, 16, pp. 245-252, 2012.

https://doi.org/10.1061/(asce)cc.1943-5614.0000261 